\title{
FLEXIBILIZACIÓN LABORAL, TELETRABAJO Y COVID-19
}

LABOR FLEXIBILITY, TELEWORKING AND COVID-19

FLEXIBILIDADE DE TRABALHO, TELEWORKING E COVID-19

\author{
María Azucena Feregrino Basurto
}

Doctora en Ciencias Sociales y Políticas, Universidad Iberoamericana de la Ciudad de México. Investigadora, Instituto de Investigaciones sobre la Universidad y la Educación (IISUE), Universidad Nacional Autónoma de México. ORCiD: 0000-0003-0146-0482. Email: maferegrino@comunidad.unam.mx, México.

\section{Recibido: 28 de noviembre de 2020 \\ Aprobado: 14 de abril de 2021 \\ DOI: https://doi.org/10.22267/rtend.212202.181}

\begin{abstract}
Resumen
Este artículo se centra en el estudio de la flexibilización laboral y teletrabajo durante la pandemia por la COVID-19. Especialmente, aborda el caso de las trabajadoras y trabajadores del sector cultural, quienes de manera repentina y, prácticamente, sin ninguna preparación previa, han tenido que realizar la mayor parte de sus actividades creativas a distancia y con distanciamiento físico. La investigación es de corte cualitativo con entrevistas en profundidad. Entre sus resultados se destacan la falta de condiciones técnicas y tecnológicas para llevar a cabo la actividad, así como las diferentes experiencias en función del género.
\end{abstract}

Palabras clave: organización del trabajo; pandemia; sector cultural; trabajo a distancia.

JEL: J1; J40; J44; J49; Z00

\begin{abstract}
This article focuses on the study of labor flexibility and teleworking during the COVID-19 pandemic. In particular, it addresses the case of workers in the cultural sector, who suddenly and practically without any prior preparation have had to carry out most of their creative
\end{abstract}


activities at a distance and with physical distance. The research is qualitative with in-depth interviews. Its results include the lack of technical and technological conditions to carry out the activity, as well as the different experiences based on gender.

Keywords: pandemic; remote working; cultural sector; work organization.

JEL: J1; J40; J44; J49; Z00

\section{Resumo}

Este artigo enfoca o estudo da flexibilidade do trabalho e do teletrabalho durante a pandemia COVID-19. Em particular, aborda o caso dos trabalhadores trabalhadores do setor cultural, que repentinamente e praticamente sem qualquer preparação prévia tiveram que realizar grande parte de suas atividades criativas à distância e com distanciamento físico. A pesquisa é qualitativa com entrevistas em profundidade. Seus resultados incluem a falta de condições técnicas e tecnológicas para o desempenho da atividade, além de experiências diferenciadas de gênero.

Palavras chave: organização do trabalho; pandemia; setor cultural; trabalho remoto.

JEL: J1; J40; J44; J49; Z00

\section{Introducción}

El confinamiento experimentado en México desde marzo de 2020, a causa de la pandemia por el virus COVID-19, ha convertido al teletrabajo en una práctica cotidiana. Sin embargo, los procesos de flexibilización del trabajo por los que se llegó a este paradigma no son nuevos. Desde hace varias décadas, la incorporación de las nuevas tecnologías de información y comunicación, además de la economía de mercado globalizada, han provocado grandes cambios en el mundo laboral.

El mercado de trabajo evolucionó bajo su influencia y nuevas exigencias. Se experimentaron mercados más abiertos y competitivos que demandaban la elevación del nivel de calificación profesional basada en el conocimiento y adaptación a las innovaciones tecnológicas. Además, se exigieron otras competencias relativas a habilidades blandas, como el potencial de adaptabilidad, flexibilidad, creatividad, trabajo en equipo, comunicación efectiva y resolución de conflictos, entre otras. 
Estos paradigmas se caracterizaron por nuevas configuraciones sociotécnicas, una gama amplia de nuevas formas de producción, de organización del trabajo, y de diversas maneras de realizarlo. Mismas que se han incorporado, experimentado, y significado de diferentes maneras por los sujetos laborales bajo contextos, tiempos y espacios diferenciados.

La conformación de una economía global y la introducción de nuevas tecnologías, contribuyeron, a partir de la última década del siglo $\mathrm{XX}$, a la redefinición de la relación entre gestión y trabajo, así como a la aparición de nuevas formas técnicas y sociales de división y organización del trabajo (Castells, 2006; Carnoy, 2001).

Bajo fuertes reestructuraciones productivas se privilegiaron, sobre todo, principios de eficiencia y competitividad. Las principales modificaciones de la gestión de la organización se pueden orientar en dos etapas, de acuerdo con sus objetivos. La primera, enfocada en la reestructuración productiva, se guiaba por principios de productividad y calidad, mientras la segunda optaba por favorecer la inversión y el empleo mediante la desregulación y la tercerización (Leyva y Rodríguez, 1997).

En este escenario, la competitividad internacional cobró un papel protagónico para la relación entre gestión y trabajo que, tarde o temprano, derivó en procesos de precarización. Esto se debe a que las estrategias de las gerencias optaron por enfrentar a su competencia a través del abaratamiento de los costos laborales y la flexibilización del proceso de trabajo, cuyos costos fueron asumidos por las trabajadoras y los trabajadores (Tokman, 2010, 2006). Esas nuevas realidades tuvieron un gran impacto en la conformación de la flexibilización laboral como la conocemos hoy.

Dado que la estructura económica de una sociedad se encuentra fuertemente relacionada con sus instituciones y decisiones políticas, las nuevas formas en las que fue organizado el trabajo no solo influyeron fuertemente en las condiciones de vida de los trabajadores, sino también de la sociedad en su conjunto. La desregulación y menor intervención del Estado (neoliberalista) contribuyeron en que las acciones flexibilizadoras de las gerencias pudieran transgredir las reglas del mercado de trabajo, establecidas formalmente hasta ese momento. Además, favorecieron a que las personas se integraran, bajo el ordenamiento de un nuevo paradigma, en esquemas laborales atípicos y precarios. 
Los planteamientos flexibilizadores cuestionaron la viabilidad del modelo jurídico de los contratos de trabajo típicos, orientados a la protección de la estabilidad en el empleo. Situación que dio lugar a elementos que permitirían definir una nueva relación de trabajo con grandes escisiones con respecto a las de antes. Asimismo, el contrato laboral fue objeto de grandes modificaciones, mientras las acciones flexibilizadoras dieron originen a una reconceptualización de las nociones de tiempo, permanencia y ubicación en el trabajo (Regini, 2003; Carnoy, 2001).

La desregulación del empleo llegó de la mano de la implementación de esquemas laborales basados en la tercerización de procesos y la subcontratación de personal. Así fue como los contratos de trabajo se flexibilizaron y dieron pie a contratos de medio tiempo, tiempo determinado, y otras formas de contratación civil como la de servicios profesionales, mejor conocida como contratación por honorarios. Además, se consolidaron otras formas de trabajo flexible como el trabajo a domicilio y el teletrabajo.

Aquellas formas de entender el tiempo, permanencia y ubicación en el trabajo, de las que se hablaba líneas arriba, estuvieron relacionadas con otros aspectos relativos a los avances en las telecomunicaciones y las tecnologías informáticas. Por un lado, se originó una tendencia de crecimiento en los servicios y de los "bienes virtuales"-como flujos financieros, transmisión de datos, sonido e imágenes, el comercio electrónico, etcétera-, que contribuyeron a la rápida expansión de las transacciones en términos globales (Leer, 2001, p. 18). Por otro lado, las técnicas de desmaterialización en directo - teléfono, televisión, Internet - o en diferido - CDs, DVDs, etc.- - fueron consideradas como alternativas al desplazamiento o a la copresencia. Ambas consideradas como dos grandes modalidades de gestión que, cada una en su momento, revolucionaron las relaciones a distancia (Lévy, 2006, p. 276).

En consecuencia, las nuevas formas de organización del trabajo, basadas en la gestión a distancia mediada por la tecnología, se suscitaron bajo una espacialidad que permitió contacto inmediato, aunque no físico, con base en la simultaneidad, y en cualquier parte del mundo - esto a pesar de llevarse a cabo, generalmente, desde los hogares de las trabajadoras y los trabajadores-.

De ahí que el concepto de teletrabajo se refiera al empleo que involucra el uso de tecnologías de información, la comunicación global y a distancia, dentro de un marco de nuevas formas 
de organización del trabajo. Mismo que, para realizarlo, como ya se ha dicho, exige una serie de competencias duras y blandas, además de condiciones ergonómicas y de seguridad que lo hagan posible.

Actualmente, el confinamiento derivado de las acciones gubernamentales que imponen el distanciamiento físico como una forma de aminorar la pandemia de la COVID-19, ha llevado a que múltiples trabajadoras y trabajadores hayan tenido que recurrir al teletrabajo sin una planeación previa. Por si fuera poco, una parte significativa de este grupo poblacional no contaba con los conocimientos, herramientas, recursos y, en general, condiciones necesarias para su implementación.

Hasta hace algunos años, esa forma de organizar el trabajo se relacionaba, principalmente, con empleos de escritorio que podían trasladarse con relativa facilidad a los espacios acordados por empleados y contratantes. Sin embargo, ahora, otro tipo de actividades y profesiones, que no necesariamente utilizaban la tecnología de manera intensiva, también se han incorporado a esta modalidad de trabajo.

Tal es el caso de las profesiones que se desenvuelven dentro del sector cultural y creativo, mismas que, en mayor o menor medida, han accedido históricamente al teletrabajo, como el trabajo de diseñadores, escritores, editores, etc. Sin embargo, muchas otras no fueron representativas de esa forma de organizar la actividad hasta la llegada de la pandemia.

En ese contexto se originaron también casos atípicos, como el de las artes escénicas, especialmente en la actividad teatral. A pesar de que ésta ha presentado, en los últimos años, diversas propuestas innovadoras en las que se han incorporado las Tecnologías de Información y Comunicación (TIC's) en sus procesos de trabajo, no era común que sus actividades se organizaran y ejecutaran casi en su totalidad a través del teletrabajo.

La pandemia de la COVID-19 llegó con una serie de demandas relativas a la forma de organizar, producir y experimentar el trabajo. En muchos sentidos retando las habilidades y conocimientos de las trabajadoras y los trabajadores de la cultura en lo relativo al uso de software, hardware, y de plataformas de socialización del trabajo profesional. Adicionalmente, se ha experimentado un traslape entre los espacios destinados al trabajo creativo con los espacios familiares y, en general, de reproducción; situación que les ha 
afectado no solo en la productividad, sino también, en las formas de significar el trabajo. Mientras que antes entendían su trabajo como una actividad cool, —es decir, divertida, que marca distancia con los cánones impuestos en las oficinas, generalmente relacionados con condiciones contrarias a la experiencia juvenil (Feregrino, 2021)—, ahora éste se ejecuta con dificultad en ambientes físicos y virtuales poco favorables para la concentración y la creatividad.

Ante las nuevas formas de organizar y producir su actividad por medio del teletrabajo, esta investigación parte de la pregunta: ¿cuáles son los componentes que estructuran y dotan de significados la labor de los trabajadores del sector cultural derivados del confinamiento por la pandemia?

A lo largo de este documento se tratará de dar respuesta a dicha interrogante mediante el desarrollo de 3 apartados, además de esta introducción. En primer lugar, se propone el planteamiento teórico metodológico desde el que parte esta investigación. Después, se aborda, desde un planteamiento teórico, el problema de la flexibilización laboral como antecedente del teletrabajo. En tercer lugar, se exponen los resultados de la investigación realizada en torno a personas que realizan teletrabajo dentro del sector cultural. Por último, se discuten las conclusiones.

\section{Metodología}

La globalización económica trajo consigo nuevas configuraciones de relaciones laborales, de formas de producción, y de organización del trabajo, entre otras. Los llamados (nuevos) estudios del trabajo de América Latina se han interesado en el análisis interdisciplinario de esas nuevas configuraciones, las formas en que las han incorporado los trabajadores, así como sus consecuencias, principalmente observables en sus derechos y condiciones laborales.

El punto de partida para estos estudios fueron las transformaciones en el mundo del trabajo originadas por la nueva economía global. Entre ellas, las reestructuraciones productivas, las formas de organización del trabajo y los cambios en las relaciones laborales derivados de los procesos flexibilizatorios. Estos estudios se interesan por las estructuras que acotan y restringen las decisiones de las personas, pero también por las subjetividades y potencialidades de acción. En ese sentido, se plantean desde una visión ampliada en sus ejes 
de investigación y en sus fundamentos teórico-metodológicos (De la Garza, 2006). Por ello, este estudio se circunscribe dentro de los estudios laborales de América Latina.

Esta investigación es de corte cualitativo con aplicación de entrevistas semiestructuradas y en profundidad. La elección de la metodología cualitativa se debe a que se ponderó su flexibilidad para trabajar con hechos sociales que aún están en movimiento, como es el caso del teletrabajo derivado de la pandemia por el virus COVID-19. Igualmente, la elección de la técnica de la entrevista facilitó una indagación con gran apertura y capaz de abordar las experiencias narradas desde los propios sujetos de estudio. Dichas narraciones se acotaron en contenidos y partes de sus vidas específicas, que dieron lugar a relatos compartidos socialmente (Piña, 1988).

En total se realizaron 18 entrevistas a personas que presentaron las siguientes características: 1) que fueran egresadas de educación superior de la Universidad Nacional Autónoma de México (UNAM); 2) trabajadoras del sector cultural de la Ciudad de México o zona conurbada; 3) que estuvieran realizando teletrabajo durante el periodo de confinamiento y por motivos de la pandemia. Cabe mencionar que, en todo momento, se procuró un equilibrio por género en las entrevistas.

Esta investigación forma parte de un estudio más amplio que se lleva a cabo en el Instituto de Investigaciones sobre la Universidad y la Educación (IISUE) en la UNAM, en donde actualmente se desarrolla el proyecto Los efectos de las Nuevas Formas de Organización del Trabajo (NFOT) en el empleo de egresados de la licenciatura en Literatura Dramática y Teatro (LDyT).

Debido a ello, la mayor parte de las personas entrevistadas son egresadas de dicha licenciatura. Tal elección también obedece a que éstas cuentan con un perfil multidisciplinario que abarca no solo el hecho teatral, sino también diversas actividades en el ámbito cultural, como la escritura, producción, dirección, diseño, investigación, actuación, administración, difusión y gestión cultural, entre otras.

Asimismo, como una forma de contrastar la realidad que experimentan durante la pandemia diversas personas que trabajan en el sector cultural, se realizaron entrevistas a egresadas y egresados de otras profesiones como Letras hispánicas, Comunicación, Diseño, e Ingeniería 
en computación. En ese sentido, la decisión preponderante fue que desempeñaran sus actividades a través de teletrabajo en empleos pertenecientes a dicho sector. Las entrevistas fueron realizadas entre el periodo de marzo a noviembre de 2020.

\section{La flexibilización laboral como antecedente del teletrabajo}

Los procesos de flexibilización, como aquellos de los que deriva el teletrabajo, no son nuevos. En la historia de las relaciones laborales se han manifestado de diferentes formas. Sin embargo, es en la era neoliberal en la que se muestran como una concepción de las nuevas doctrinas gerenciales, bajo el paradigma de la liberalización de los mercados (De la Garza, 2000).

Las premisas de competitividad y adaptabilidad llevaron a las gerencias a construir, en la práctica, dos dimensiones de flexibilización. La primera, la interna, se relaciona con las modificaciones de las condiciones de trabajo generalmente pactadas en un contrato de trabajo. La segunda, la externa, se orienta al uso de la fuerza laboral en un esquema diferente al tradicional contrato de trabajo (López, 2005, p. 43).

Bajo la flexibilización interna, las gerencias modifican la organización de la fuerza laboral dentro del proceso de trabajo y eliminan los puestos que no cumplen con sus necesidades cambiantes. A través de este tipo de flexibilización, las gerencias persiguen la adaptabilidad y procuran hacer frente a los cambios tecnológicos, principalmente, mediante la formación de trabajadoras y trabajadores polivalentes y multitareas (De la Garza 2000).

En lo que se refiere a la flexibilización externa, existe un énfasis creciente en la desregulación del empleo. Las reglas para la contratación y despido se liberalizan (Regin, 2003), pues suceden de una manera más sencilla gracias a nuevas disposiciones legislativas o administrativas (p. 257).

A través de la flexibilización externa, se pretende hacer frente a aspectos como las fluctuaciones en la demanda, mediante un ajuste en la producción y en la fuerza de trabajo. En este nuevo esquema se promueve la disminución de las personas que trabajan de base, la tercerización de procesos y la subcontratación de personal - aunque, también se promueve el uso de personal eventual y por honorarios - 
Asimismo, la flexibilización externa se explica por la transferencia de contratos estándar —es decir, de contratos por tiempo indefinido, de tiempo completo y con un empleador claramente identificable (Bensusán, 2009, p. 27)—, hacia contratos atípicos — como los contratos por medio tiempo, por tiempo determinado, por obra, por honorarios o contratos civiles y, en ocasiones sin un "patrón" identificable_- Esta forma de flexibilización puede originarse, también, por medio de la externalización de procesos o funciones.

Bajo los contextos de la reestructuración productiva, la flexibilidad laboral se enfoca, sobre todo, en hacer ajustes a la gestión de la producción mediante nuevos esquemas de contratación orientados a la tercerización o subcontratación. En esos términos, la tendencia a externalizar es una de las principales características de las nuevas estrategias empresariales.

Desde la década de los años ochenta del siglo XX, diversas organizaciones desarrollaron una tendencia a tercerizar parte de sus procesos productivos, sobre todo, aquellos que no se consideraban medulares o críticos. Éstos son transferidos a proveedores especializados bajo la premisa de obtener mayor rentabilidad al trasladar las obligaciones de quienes fungen como patrones a otras personas u organizaciones (Bouzas, 2008, p. 139).

Para autores como De la Garza (2007), la subcontratación laboral no representa un tema nuevo dentro del capitalismo. No obstante, es novedosa en cuanto a la legitimación que de su uso hace el Estado. En ese sentido, la subcontratación es el concepto más representativo de la flexibilidad.

Iranzo y Leite (2006) definen a la subcontratación como aquellas formas de contratación donde no existe una relación de dependencia o subordinación entre contratantes y contratados o, en su caso, dicha responsabilidad es transferida a un intermediario (p. 404). Para establecer una relación de subordinación se requiere analizar diferentes criterios que dependen del sistema jurídico vigente. Sin embargo, existe un indicador que usualmente la determina; esto es el grado de control ejercido por la persona que emplea hacia aquella empleada (Tomei, 1989, p. 3).

Los esquemas de subcontratación suelen transgredir las condiciones de trabajo de las personas subcontratadas. Entre sus afectaciones destacan, por ejemplo, que regularmente no gozan de los mismos derechos y garantías sociales que las personas que trabajan de base, sus 
salarios suelen ser más bajos y sus jornadas laborales más largas. Asimismo, tienen mayor propensión a perder su empleo y suelen enfrentarse a defraudaciones por problemas derivados de las insolvencias de las empresas subcontratistas (Bouzas, 2008; De la Garza, 2005).

En estos esquemas se establecen las condiciones propicias para que sea un tercero el que responda de los compromisos frente a las trabajadoras y los trabajadores, y no la empresa que se ve beneficiada con el trabajo (Bouzas, 2008, p. 141). Lo que es peor, muchas veces, las personas subcontratadas no mantienen una relación de dependencia o subordinación con su contratista — o ésta es maquillada para que parezca inexistente-.

Josefa Montalvo (2005) señala que la condición de subordinación generalmente se asocia con las siguientes exigencias a los trabajadores: 1) que asista al lugar de trabajo, 2) que cumpla con un horario fijo, y 3) que se comprometa a seguir las órdenes de aquella persona que tenga la figura de patrón.

Por otro lado, la relación laboral subordinada puede identificarse bajo dos premisas. En la primera, si bien es cierto que en la mayoría de las ocasiones las trabajadoras y los trabajadores eligen el lugar de trabajo y deciden cómo organizar su jornada laboral, la persona que emplea es quien establece las características de los productos o servicios requeridos y, además, es quien fija los términos y condiciones de entrega y pago de éstos. La segunda se observa cuando el pago que se realiza a la persona contratada es en función del trabajo incorporado en la producción de cierto bien o servicio, mismo que se distingue del que se haría por el valor del producto elaborado o del servicio brindado.

Ahora bien, dentro de las diferentes formas de empleo flexible, existen otras variantes como el trabajo a domicilio y el teletrabajo. El trabajo a domicilio se ubica, tradicionalmente, en los inicios del capitalismo y de la era industrial. Sin embargo, podemos encontrar sus orígenes siglos atrás, inclusive antes de la Revolución Industrial. Aunque es durante este periodo, entre la segunda mitad del siglo XVIII y principios del XIX, que se extiende su uso y, en muchos casos, también su nivel precariedad (Thompson, 1975).

El Convenio 177 de la Organización Internacional del Trabajo (OIT, 1996) define el trabajo a domicilio como el trabajo que una persona realiza en su domicilio o en otros locales que 
escoja, distintos de los locales de trabajo del empleador; a cambio de una remuneración; y con el fin de elaborar un producto o prestar un servicio conforme a las especificaciones del empleador, sin importar quién proporcione el equipo, los materiales $\mathrm{u}$ otros elementos utilizados para ello, a menos que esa persona tenga el grado de autonomía y de independencia económica necesario para ser considerada como trabajadora o trabajador independiente en virtud de la legislación nacional o de decisiones judiciales.

Para Tomei (1989) el tema del trabajo a domicilio se inserta en el debate actual sobre trabajo flexible, aunque éste, en realidad, representa una de las formas más antiguas de trabajo atípico. No obstante, ahora existen diferencias marcadas. Anteriormente, el trabajo a domicilio se relacionaba con actividades de baja productividad que ocupaban mayoritariamente mano de obra femenina y no organizada, en condiciones de sobreexplotación, precariedad y pobreza. Mientras, en épocas más recientes, ha cobrado mayor importancia en sectores de punta y con fuerza de trabajo mayormente calificada (Tomei, 1989, p. 7).

Adicionalmente, existen otros trabajos que comparten características de trabajos atípicos y flexibles, que igualmente han tenido gran relevancia en las economías avanzadas, y que se han desarrollado a la par del auge de las tecnologías informáticas. Tal es el caso del trabajo remoto también conocido como "teletrabajo". El teletrabajo es considerado como una nueva forma de organización o ejecución del trabajo, realizado principalmente a distancia, y mediante el uso intensivo de las técnicas informáticas o de comunicación (Thibault, 2000, p. $32)$.

La OIT (1990) propuso una definición diferenciada de teletrabajo: por un lado, la propone como una forma de trabajo que se realiza en una ubicación fuera de las oficinas centrales o de las instalaciones de producción, que separa a la persona trabajadora del contacto directo con otras ubicadas allí; por otro lado, lo entiende como el proceso mediante el cual la aplicación de tecnología facilita la comunicación a distancia (Di Martino, 2001, p. 11).

El teletrabajo presenta algunas semejanzas con el trabajo a domicilio. Estas dos formas de trabajo se relacionan con procesos de globalización, se originan en contextos de flexibilización y repunte del trabajo atípico y precario. Por otro lado, entre las principales diferencias del teletrabajo con el trabajo a domicilio se suelen resaltar: el uso intensivo de 
tecnologías informáticas; el grado de autonomía y de independencia económica, el cual podría llevarlos a ser considerados como trabajadores independientes, o por cuenta propia, sin perder su categoría de teletrabajador; y la posibilidad de que los resultados del trabajo productos o servicios-, los puedan recibir tanto empleadores como clientes.

Constantemente se origina bajo dos esquemas. Uno es el relativo a los procesos de tercerización en los que, en teoría, aquellas actividades que no forman parte del núcleo principal de la producción de la empresa son subcontratadas. Esta forma de contratación suele tener un carácter civil, al realizarse en calidad de servicios profesionales, sin contar con ninguna prestación social. Sin embargo, aquí hay una distinción importante que hay que anotar en cuanto al uso y pertenencia de los medios de producción, los cuales podrían dejar entrever una forma velada de relación laboral.

Otra forma es la laboral, en la que la empresa que subcontrata responde por las prestaciones de la persona subcontratada. La actividad usualmente se lleva a cabo en el domicilio de la trabajadora o del trabajador. Muchas veces el hardware y el software son proveídos por la empresa contratante, aunque no pasa lo mismo con el mobiliario y otros servicios indispensables para la ejecución del trabajo.

Adicionalmente, existe una vertiente en la que se requiere a la persona empleada que trabaje a distancia de manera indefinida bajo un contrato laboral. En este caso, para que el teletrabajo se lleve a cabo, usualmente se parte de la voluntad y acuerdo de ambas partes. Aunque muchas veces, en la práctica, la empresa suele exigirlo de forma unilateral; es decir, sin pedir el consentimiento de la trabajadora o del trabajador.

Esta situación lleva al cuestionamiento sobre una de las particularidades fundamentales de la relación laboral, que es la capacidad que se concede a la parte empleadora para modificar dicha relación unilateralmente y adaptarla a los cambios que se producen en su entorno, toda vez que garantice la continuidad organizacional. Esa adaptabilidad se canaliza a través de diferentes instrumentos jurídicos que conforman los denominados poderes organizativos empresariales, entre los que se incluyen el poder de dirección, de movilidad geográfica, y de modificación sustancial (Del Rey, 2005, pp. 62-63). 
Actualmente, toda vez que las políticas de gobierno se han encaminado a tratar de mitigar los efectos de la pandemia a través del confinamiento, el teletrabajo se ha convertido prácticamente en una modalidad obligada para muchas personas que laboran, sobre todo, en el sector servicios. De tal forma, en medio de la contingencia, no hubo oportunidad de resolver aspectos importantes, como los acuerdos por los que se pactan derechos y obligaciones de las partes relativos al trabajo a distancia. Sobretodo en países como México, en donde, hasta hace poco, no había una normatividad que regulara dicha forma de trabajo. Situación que ha sido aprovechada por diversos empleadores, quienes han flexibilizado y precarizado aún más el trabajo.

En el caso del sector cultural, aunque la flexibilización laboral ya era observable desde tiempo atrás — sobre todo desde la adhesión al Tratado de Libre Comercio de América del Norte (TLCAN) - el teletrabajo no era una realidad para una gama de actividades tan amplia.

\section{Resultados}

El panorama anterior sirve para enmarcar históricamente muchas de las realidades que se encuentran viviendo en la actualidad los trabajadores del sector cultural, derivadas de la flexibilización laboral. Aunque, también, mantienen una relación directa con el tipo de actividad que desempeñan y la forma en que se concibe socialmente el trabajo en dicho sector. En otros estudios se ha resaltado que las trabajadoras y los trabajadores de la cultura, tradicionalmente, han visto afectados sus derechos laborales debido a que, en los contextos en los que se desenvuelven, involucran ingresos irregulares, largos periodos de desempleo y, hasta, trabajo gratuito - por el llamado amor al arte-. Condición que hace proclive a este grupo laboral no solo a la precarización, sino también a las estafas y los engaños (Feregrino, 2021a).

En el caso de las personas entrevistadas, a pesar de contar con empleo, la mayoría refiere inconformidad en cuanto a elementos relativos a la flexibilización, particularmente relacionados con la subcontratación y el teletrabajo. Los esquemas bajo los que se emplean son disímiles, aunque la mayoría de ellas no cuenta con un contrato por escrito que establezca sus derechos y obligaciones. Algunas, incluso, son contratadas bajo la categoría de servicios profesionales independientes, por lo que se rigen por el ordenamiento del derecho civil. 
Es destacable que sus condiciones de trabajo se encuentran insertas en un vacío de regulación y en un escenario que les lleva a experimentarse como independientes o cuentapropistas. Cuando, en la práctica, constantemente realizan su actividad bajo condiciones de subordinación laboral. Es decir, bajo las órdenes de un patrón. Aunque, la mayoría de las veces les cuesta identificarlo como tal debido a que llegan a estar insertos en múltiples procesos de subcontratación.

A pesar de ello, refieren como algo beneficioso el no contar con un contrato que les imponga, por ejemplo, un horario de trabajo, aunque, de cualquier forma reconocen que siempre han contado con fechas de entrega establecidas. Para este grupo laboral el beneficio radica en tener la posibilidad de organizar su jornada como mejor les plazca. No obstante, esta condición cambió con la pandemia, ya que aseguran que el nivel de supervisión al que son sometidos ahora aumentó y que, incluso, se les llega a exigir estar conectados y en línea mucho más tiempo de lo usual.

En este medio prevalece una fuerte simulación laboral que se propicia, principalmente, por un mal entendimiento del trabajo creativo y por razón de conveniencia de los contratistas entre los que se incluye el gobierno- quienes se benefician económicamente al enaltecer su quehacer y vocación - al menos en apariencia-, en el marco de lo artístico, social y hasta altruista.

En el trabajo de campo se encontró que no existe un planteamiento de autoempleo o de emprendimiento por parte de este grupo laboral, pues consideran que su actividad está siendo supervisada continuamente y que, incluso, requieren del visto bueno de otras personas que asumen como sus jefes. Consideran que su actividad representa una especie de eslabón que forma parte de un proceso en el que se inserta su trabajo. Además, plantean que no cuentan con los recursos económicos, ni el capital social para emprender un negocio por cuenta propia. De este modo, identifican su actividad como servicios profesionales solo por el hecho de proporcionar un recibo de honorarios para poder cobrar. Curiosamente, dicha situación es interpretada como negativa únicamente por los tramites administrativos y contables que implican, y no por la pérdida de derechos sociales derivados del empleo.

Como se ha podido observar en el apartado metodológico, en este estudio la edad no fue considerada como un criterio metodológico. Sin embargo, las personas entrevistadas 
oscilaron entre los 30 y 50 años. Cabe destacar que aquellas que se encontraban en un rango de edad más cercano a los 50 años se mostraron mucho más preocupadas por la falta de acceso a servicios de salud y por el derecho a la jubilación. Mientras las personas más jóvenes mencionaron que, por esa misma condición de juventud, el tema de la seguridad social no estaba dentro de sus preocupaciones. Aunque resaltaron que con la pandemia quizás éste debería ser un tema en el que deberían prestar más atención.

La mayoría de trabajadoras y trabajadores que realizan sus actividades por el esquema de honorarios refirieron que empezaron a laborar de este modo por la falta de otro tipo de oportunidades. Relatan que al egresar de sus carreras universitarias tenían la ilusión de contar con un empleo formal, sin embargo, con el paso del tiempo, fueron aceptando trabajos temporales y menos seguros, que usualmente conseguían por recomendación de algún amigo, conocido, o profesor de la universidad. Incluso, en tiempos cercanos al egreso, muchas veces tuvieron que participar en trabajos sin recibir ninguna retribución económica, solo por adquirir experiencia, aunque con el tiempo se les empezaba a incluir en proyectos remunerados. En ese sentido, esa forma de allegarse al trabajo funciona como una suerte de pasantía del tipo informal, es decir, no regulada por las instituciones universitarias. Misma que en otros estudios se ha encontrado que se relaciona con los sentidos simbólicos y culturales de "sufrir para merecer", que se le suelen dar a la profesionalización de las actividades artísticas (Feregrino, 2021b).

Aquel tipo de trabajo es aceptado de buena gana por la mayoría de las personas entrevistadas, pues lo describen como menos rígido y libre, ya que les da mayor oportunidad de organizar sus tiempos, aunque no por eso cuentan con más autonomía. Igualmente, como se ha establecido previamente, esa libertad no necesariamente se ajusta del todo a la realidad, pues cuentan con plazos de entrega de sus actividades, generalmente, no negociables. Además, como el resultado de su labor suele alimentar otros procesos de un trabajo colectivo, debe ajustarse a tiempos y espacios establecidos para su entrega, discusión y retroalimentación.

A pesar de que algunas personas ya hacían teletrabajo antes de la pandemia, durante la entrevista destacaron que la condiciones cambiaron con el confinamiento. Primero, nadie reporta haber tenido un periodo tan largo e ininterrumpido de teletrabajo previo. Segundo, el teletrabajo no necesariamente ocurría desde los hogares de los trabajadores, sino en otros espacios que consideraban más propicios para la creatividad, pero también para la 
socialización, como el campus universitario. Tercero, los equipos de cómputo en los que realizaban su actividad podían no ser propiedad de la organización para la que trabajaban, o de los trabajadores, sino que muchas veces eran de uso público. O bien, alternaban su uso con otros dispositivos como los celulares o tabletas, o con equipos de uso familiar. Cuarto, no todo era teletrabajo, existían tiempos y espacios destinados para la convivencia física, tanto en lo relativo a lo laboral, como en actividades de esparcimiento y recreación. Quinto, había mayor equilibrio y separación entre la vida laboral y familiar.

Si bien muchas de las condiciones cambiaron —a veces por decisión unilateral—, también, se modificaron las formas en que éstas fueron significadas por las trabajadoras y los trabajadores. Por ejemplo, narran que, a partir de la pandemia, han reflexionado más sobre sus condiciones laborales y, en general, sobre la calidad de sus empleos. El resultado muchas veces ha sido desalentador, pues consideran que no se encuentran tan satisfechos ahora con sus trabajos como lo estaban antes de iniciada la cuarentena.

La mayoría trabaja por proyectos, los cuales suelen ser esporádicos, muchas veces bajo contratos verbales o informales, sin prestaciones laborales, ni acceso a la seguridad social. Manifiestan que en el sector cultural es muy difícil ahorrar, no solo porque el trabajo es esporádico, sino también, por los bajos ingresos que se perciben y el largo tiempo en el que se consigue cobrar. Por lo que, en contingencias, como la actual emergencia sanitaria y laboral, no cuentan con formas de resolver todas sus necesidades económicas. Aunado a ello, la ausencia de seguridad social y la pausa obligada en el desarrollo de su actividad, han provocado una gran incertidumbre en cuanto a su futuro personal y profesional.

Al momento en que la Organización Mundial de la Salud (OMS) declaró la pandemia por COVID-19, las actividades artísticas y del ámbito considerado como cultural, principalmente todas aquellas relativas a las artes escénicas, sufrieron una de las peores crisis de su historia reciente. Esto se debe a que gran parte de la comunidad que laboraba en dichas actividades vio suspendidos o extintos sus empleos. Algunas de las personas que pudieron permanecer activas tuvieron que recurrir al teletrabajo de tiempo completo.

La necesidad de confinarse bajo un escenario de desempleo, o empleo precario, y con prácticamente nulos ahorros, llevó a que diversas personas emancipadas y que vivían solas, o con sus parejas, se vieran en la necesidad de regresar a los hogares nucleares de origen ante la 
imposibilidad de seguir pagando un lugar en donde vivir. Otra condicionante de esta decisión fue la necesidad de atender y cuidar de familiares vulnerables, principalmente de adultos mayores.

Las personas entrevistadas refirieron, de manera generalizada, que la modificación de sus condiciones laborales, derivadas del teletrabajo y la cuarentena, ha mermado fuertemente su bienestar emocional, pues han experimentado una pérdida de independencia y libertad, no solo en su trabajo, sino también en la vida misma.

(...) voy a sonar súper fatalista, pero creo que la mayoría de mis sentimientos no han cambiado para bien (...). Yo no vivía con mis papás. Eso es un dato muy, muy importante. Entonces, no sé, yo me sentía mucho, mucho más tranquila, más libre. Y de cuatro meses para acá he sentido que todo se ha vuelto a descomponer. (D. E., comunicación personal, 10 de agosto, 2020)

En general, resaltaron el impacto que ha tenido en sus vidas la dilución de los límites entre la vida familiar y laboral. Algo que echan de menos son los espacios habituales donde solían interactuar, ya que consideran se han limitado sus actividades de integración, esparcimiento y ocio. Por lo que, incluso, aquellas personas que hacían teletrabajo antes de la pandemia desean volver a hacer sus actividades fuera de casa.

No me gustaría seguir trabajando a distancia una vez que termine la cuarentena porque prefiero salir de mi casa, separar claramente mi horario de trabajo y mis actividades familiares, conversar casualmente con compañeros, convivir fuera al final del día o en un almuerzo. (M. R., comunicación personal, 27 de julio, 2020)

Otro hecho que ha tenido un gran impacto en estas personas, sobre todo en las mujeres, son las actividades de cuidado a la familia. Tanto estas últimas, como los quehaceres domésticos, parecen seguir recayendo principalmente en las mujeres, quienes manifestaron tener dificultades para cumplir con sus jornadas de trabajo de forma continua debido a las múltiples interrupciones, demandas familiares y, en general, por las llamadas dobles jornadas.

Es un poco complicado separar el horario de trabajo y empezar las labores del hogar y actividades familiares. A veces estoy trabajando y mi familia me exige que termine de 
trabajar. Existe una mayor presión que cuando trabajo fuera. Creo que todavía las mujeres trabajan más en el hogar que los hombres, por lo tanto, es más difícil para las mujeres con hijos trabajar a distancia. (A. C., comunicación personal, 23 de octubre, 2020)

Por lo mismo, resaltaron la necesidad de un espacio más amplio, tranquilo y sin distracciones para trabajar en condiciones de confinamiento. Una de las principales carencias que resaltan es la falta de un lugar específicamente destinado para realizar su labor. Por ejemplo, recurrentemente refieren tener que trabajar en espacios diseñados para otro tipo de actividad o inactividad.

Mi departamento es muy pequeño, muy, muy pequeño, entonces no hay como dónde trabajar ahí de fijo y cómodamente. En realidad, ando del comedor a la recámara buscando dónde estar cómoda. Una vez que tenía que grabar unos audios, de plano me tuve que meter al baño a grabar porque no había forma de que no sonaran todos los ruidos de todo mundo". (J. C., comunicación personal, 15 de julio, 2020)

Asimismo, hombres y mujeres destacaron la urgencia por salir y volver a hacer sus actividades cotidianas fuera del hogar. En ese sentido, en la expectativa de trabajar afuera y no adentro de casa, entran en juego diversos componentes objetivos y subjetivos. En primer lugar, "el afuera" implica para estas personas la relación con el espacio público, en el cual suelen llevar a cabo muchas de sus actividades. El mismo punto se relaciona con el deseo de volver a "la normalidad" y olvidarse de "la nueva normalidad", la cual las excluye tácitamente de la vida pública.

En segundo lugar, "el afuera" se vincula con el carácter relacional y colaborativo de la actividad. "El afuera" conlleva relacionarse con otras personas en contextos particulares, por lo que existe una gran añoranza por trabajar nuevamente rodeadas de colegas y público. El trabajo en las artes escénicas, por ejemplo, está destinado a la interacción y requiere de espectadores con quien llevar a cabo la actividad convivial. Aunque es innegable que las limitantes del aislamiento han contribuido para que el convivio se adapte a la situación actual.

(...) al ser Facebook (...) te va a aparecer fulanito de tal está transmitiendo en vivo, entonces ese tipo de herramientas creo que, hoy en día, funcionan por la misma 
situación de que vas a interactuar con el público que esté activo en ese momento en Facebook, y vas a saber sus reacciones, va a haber comentarios, quizá uno no esté... o sea, al pendiente, pero al final de cuentas es como esa adrenalina que corre. (E. T., comunicación personal, 15 de mayo, 2020)

El confinamiento no ha sido el único tema abordado como una condición de exclusión. Las personas entrevistadas también se han sentido excluidas debido al acceso a Internet y por las herramientas y conocimientos que necesitan desplegar para realizar su trabajo a distancia.

Por un lado, el problema del acceso y calidad del Internet fue uno de los temas más mencionados por las personas entrevistadas. Aunque algunas aseguraron que tuvieron que recurrir a los datos de sus celulares como alternativa para realizar su trabajo, muchas otras ya contaban con algún servicio de Internet en sus hogares desde antes de comenzar la cuarentena. Sin embargo, manifestaron no haberse dado cuenta de lo malo que era ese servicio hasta que tuvieron que trabajar en casa el día completo, a la par de toda su familia.

Sí, creo que lo más complicado ha sido el Internet. Creo que... por ejemplo, no somos las únicas que lo utilizamos (...) entonces, pues se satura el Internet. Llega un punto en el que se vuelve súper lento (...) ahorita ya tuvimos como la fortuna de poder resolverlo con el cable directo del internet. Entonces, así es como hemos podido transmitir, por ejemplo, en Cenizas [obra de teatro transmitida por Facebook Live y YouTube], para que no se caiga todo. (B. P., comunicación personal, 05 de agosto, 2020)

Derivado de ello, otras personas externaron fuertes críticas a las compañías que proveen estos servicios y a las instituciones que las regulan, ya que consideran son muy caros y deficientes.

El principal problema es la mala calidad de los servicios de conectividad a Internet. En mi casa hemos probado todos los proveedores de acceso a Internet. Incluso ya regresamos al primer proveedor. Todos venden básicamente lo mismo, paquetes que cuestan tanto como la velocidad de descarga, pero ni siquiera publicitan la velocidad de carga de datos, y tampoco informan que sus redes se saturan a ciertas horas debido a que muchas casas se conectan a la vez. El resultado es que muchas veces, en las 
conferencias de trabajo, no me escuchan, se corta, se congela la imagen, etc. Aún peor, no hay a quién reclamarle. (A. C., comunicación personal, 07 de octubre, 2020)

Otra condición de exclusión se origina por los requerimientos técnicos y por la propiedad de hardware y software necesarios para realizar su labor. En el trabajo de campo se encontraron diferencias significativas por tipo de contratación de las trabajadoras y los trabajadores. Las personas con empleos subordinados vieron cubiertas sus necesidades en dichos rubros por parte de sus empleadores.

En una situación óptima, debería contar con un espacio reservado, aislado, dentro de mi casa, para realizar el trabajo. Por limitaciones de espacio, solo cuento con un escritorio, una silla medianamente ergonómica y la empresa [me] provee monitor, teclado, mouse, o equipo de conectividad, conforme a los requerimientos del empleado. (L. M., comunicación personal, 21 de septiembre, 2020)

Sin embargo, las personas subcontratadas y quienes realizaban sus actividades por el esquema de honorarios, tuvieron que resolver por su cuenta sus carencias. Éstas manifestaron una gran escasez de recursos y herramientas, sobre todo digitales, para llevar a cabo su trabajo. Incluso, muchas veces, se enfrentaron a la necesidad de tener que compartir la computadora con otras personas integrantes de su familia, lo que limitó su tiempo productivo. Nuevamente, una alternativa fue trabajar desde sus celulares, o comprar equipos de doble uso, o nuevos a crédito. Mientras la carencia de software, en algunos casos, fue resuelta mediante servicios de compartición tipo torrents.

La tercera condición de exclusión se relaciona con el conocimiento, experiencia y gusto por el uso de la tecnología. A pesar de que, en épocas recientes la tecnología se ha convertido en un componente muy importante para el desarrollo del sector cultural y creativo $-\mathrm{y}$ de que las últimas generaciones han innovado en la concepción de nuevas tendencias artísticas mediadas por la tecnología-, la mayoría de las personas entrevistadas, con excepción de quienes estudiaron computación, se asumieron inseguras y con conocimientos y habilidades limitadas para el uso intensivo de TIC's que el teletrabajo demanda. En muchos casos el tema derivó en críticas a su formación profesional pues, en su opinión, la universidad debió haberles proveído de las competencias, conocimientos y habilidades tecnológicas necesarias para enfrentar el mundo laboral, independientemente de su área de estudio. 
(...) pero siento yo que falta muchísima infraestructura y tecnología y demás para aprender a trabajar, sobre todo, toda la parte de diseño, en computadoras. No hay ninguna opción para nosotros, para aprender a usar AutoCAD, ni True Lab, ni Isadora. Entonces, si lo aprendemos a usar es por fuera. (S. M., comunicación personal, 31 de marzo, 2020)

La cuarta condición que consideran excluyente, y que les impide realizar su actividad de manera adecuada y profesional, es la disponibilidad de energía y luz eléctrica. En algunas zonas de la Ciudad de México y la zona conurbada, en donde residen las personas entrevistadas, se experimentan cortes continuos de energía eléctrica. Situación que interrumpe los servicios de conectividad e Internet. Además, de la afectación a los dispositivos electrónicos que no se precargan y requieren conectarse para funcionar, como el caso de computadoras de escritorio, escáneres, módems y algunos teléfonos de línea fija.

Otro aspecto relacionado con este tema, y que destacaron en el trabajo de campo, fue el costo del servicio de luz eléctrica — también de Internet-. Las facturas de este servicio han aumentado debido a que muchas personas se encuentran congregadas en sus hogares las 24 horas del día, utilizando en exceso la energía eléctrica. Situación que ha llegado a propiciar, en ciertos casos, la suspensión del servicio por falta de pago.

Como se mencionó al inicio de este documento, hasta hace poco, en México no estaba regulado el teletrabajo. Si bien el artículo 311 de la Ley Federal del Trabajo (LFT) considera el trabajo a domicilio, es hasta ahora, por la pandemia, que se ha aceptado una propuesta para reformar dicho artículo y adicionar un capítulo para regular al teletrabajo al nivel nacional. Sin embargo, la LFT solo contempla a trabajadores bajo relación laboral subordinada. Lo que deja fuera a todas las personas que realizan actividades por cuenta propia, por servicios profesionales y a todas aquellas que son subcontratadas sin que se lleguen a formalizar sus contratos de trabajo. Bajo esta nueva regulación la parte patronal estaría obligada a pagar los servicios de luz, Internet y telefonía, aunque con algunas restricciones.

Por último, las trabajadoras y trabajadores resaltan que todas esas obligaciones y demandas relativas al trabajo en casa lo han hecho monótono, aburrido y hasta desgastante. Les recuerda a las dinámicas "tipo oficina" de las que siempre buscaron distanciarse. Consideran que su trabajo es creativo y que, por lo mismo, requiere de condiciones especiales para 
realizarse. Además, parte del gusto que encontraban antes en su trabajo tenía que ver con las dinámicas en las que éste se llevaba a cabo, pues eran divertidas e interesantes. Lo que es peor, de manera simbólica señalan haber perdido parte de la esencia misma de la actividad artística y cultural: la libertad.

\section{Conclusiones}

A lo largo de este documento se ha observado cómo, en las últimas décadas, la conformación de una economía globalizada trajo consigo la necesidad de que las unidades de negocios funcionaran a escala planetaria en tiempo real, mediante el uso de tecnologías informáticas novedosas (Castells, 2006). A la par, esas tecnologías contribuyeron a la aparición de nuevas formas de organización del trabajo y a la redefinición histórica de la relación entre gestión y trabajo (Carnoy, 2001). Este es el caso del teletrabajo, entendido como aquel trabajo efectuado por una persona - ya sea empleada o trabajadora por cuenta propia-, quien desarrolla sus actividades mediadas por tecnologías informáticas y de comunicación desde una ubicación a distancia, generalmente desde el hogar de la trabajadora o del trabajador.

Aunque no es posible hablar de condiciones homogéneas de desarrollo productivo y organizacional, pues los nuevos paradigmas basados en la producción informacional tuvieron lugar dentro de contextos y estructuras disímiles. Un ejemplo de ello son las trayectorias de empleo/ocupación de cada sociedad en particular (Castells, 2006, p. 269). Las cuales nos hablan, en lo general, del mercado laboral, pero también, de otros aspectos como la especialización, experiencia, conocimientos y destrezas adquiridas a través de la formación ocupacional. Más aún, existen otros factores a considerar como las reglas formales e informales que regulan el trabajo a distancia. Esto sin dejar de lado aspectos subjetivos, como los gustos y preferencias de los trabajadores.

De tal suerte, los nuevos paradigmas productivos enfocados al uso intensivo de tecnología, mayormente flexibilizados y tercerizados, requirieron de perfiles laborales con competencias duras y blandas; por un lado, se demandaban capacidades cognitivas y habilidades técnicas e informáticas; por otro, fueron fuertemente valorados aspectos como la creatividad, adaptabilidad, flexibilidad, trabajo en equipo, comunicación efectiva y resolución de conflictos, entre otros. 
Uno de los aspectos más emblemáticos de la flexibilización laboral, derivado de una estrategia gerencial orientada a la competitividad, se experimentó bajo la tercerización de procesos y la subcontratación de personal, dando lugar a nuevos esquemas laborales como los servicios profesionales, la subcontratación y el trabajo por cuenta (De la Garza, 2000). En adición a esos esquemas, se presentaron otros relacionados con el trabajo a distancia que, si bien ya tenían como precedente del trabajo a domicilio, adquirieron otro sentido con el uso intensivo de las tecnologías informáticas y de comunicación, en la virtualidad y a través de la conectividad.

En los contextos globalizados, las tecnologías de información y comunicación también afectaron las formas de producción y organización del trabajo del sector cultural. Sobre todo, aquellas que mantenían una relación más cercana con los procesos informatizados, como las actividades relativas al cine, el video, algunos videojuegos, y los nuevos medios de comunicación.

Por último, se analizaron las condiciones estructurales y subjetivas en las que las trabajadoras y los trabajadores del sector cultural organizan sus actividades a través del teletrabajo. Dentro de los resultados del caso de estudio, se resaltaron:

- Condiciones precarias de trabajo.

- La falta de un lugar específicamente destinado para el teletrabajo.

- No contar con las condiciones ergonómicas adecuadas para el trabajo a distancia.

- Dificultades técnicas y de conexión a Internet.

- Condiciones diferenciadas de trabajo por género.

- Problemas para concentrarse, exceso de horas de trabajo y baja productividad.

- Merma en su bienestar emocional.

- Condiciones de trabajo diferenciadas de acuerdo con el tipo de contrato establecido por su contratante.

- Deficiencias en la formación profesional por falta de contenidos relativos al uso de tecnología. 


\section{Referencias}

(1) Bensusán, G. (2009). Estándares laborales y calidad de los empleos en América Latina. Perfiles Latinoamericanos, 17(34), 13-49.

(2) Bouzas, J. (2008). Régimen Contractual, Discriminación y Situación Laboral de la Juventud en México, México: Consejo Nacional para Prevenir la Discriminación.

(3) Carnoy, M. (2001). El trabajo flexible en la era de la información. Alianza Editorial.

(4) Castells, M. (2006). La era de la información. Siglo XXI Editores.

(5) De la Garza, E. (2000). La flexibilidad del trabajo en América Latina. En Tratado Latinoamericano de Sociología del Trabajo (pp. 148-177). FCE.

(6) De la Garza, E. (2005). Sindicatos y nuevos movimientos sociales en América Latina. Clacso.

(7) De la Garza, E. (2006). Del concepto ampliado de trabajo al de sujeto laboral ampliado. En C. López, et al. (Eds.). Vías y escenarios de la transformación laboral: Aproximaciones teóricas y nuevos problemas (pp. 25-52). Editorial Universidad del Rosario.

(8) De la Garza, E. (2007). Hacia un concepto ampliado de Trabajo [ponencia]. Seminario sobre Trabajo, relaciones laborales y Regulación, Buenos Aires, Argentina.

(9) Del Rey, S. (2005). Relaciones laborales y nuevas tecnologías. Reflexiones introductorias. Cuadernos de Derecho Judicial.

(10) Di Martino, V. (2001). The high road to teleworking. International Labour Organization.

(11) Feregrino, A. (2021a). Arte, trabajo a distancia y COVID-19. [Inédito].

(12) Feregrino, A. (2021b). El arte no se vende. [Inédito].

(13) Iranzo, C. y Leite, M. (2006). La subcontratación en América Latina. En De la Garza Toledo (Coord.). Teorías Sociales y Estudios del Trabajo: nuevos enfoques (pp. 404433). Anthropos.

(14) Leer, A. (2001). La visión de los líderes en la era digital. Prentice Hall.

(15) Lévy, J. (2006). Geografía y mundialización. En D. Hiernaux y A. Lindón (Dir.). Tratado de Geografía humana (pp. 273-302). Anthropos-UAMI.

(16) Leyva, M. y Rodríguez, J. (1997). Sindicalismo y democratización del trabajo. Iztapalapa. Revista de Ciencias Sociales y Humanidades, (42), 277-300. 
(17) López, D. (2005). Mitos, alcances y perspectivas de la flexibilización laboral: un debate permanente. En J. Ensignia (Ed.). Mitos y realidades del mercado laboral en Chile (pp. 37-58). Friedrich Ebert Stiftung.

(18) Montalvo, J. (2005). Flexibilización del contrato de trabajo. Letras jurídicas, (12), 269279.

(19) Organización Internacional del Trabajo [OIT]. (1996). Convenio sobre el trabajo a domicilio, número 177. https://www.ilo.org/dyn/normlex/es/f?p=NORMLEXPUB:12100:0::NO::P12100_ILO_ CODE:C177

(20) Piña, C. (1988). La Construcción del "Sí Mismo" en el relato autobiográfico. Documento de Trabajo No. 383. Programa FLACSO Chile.

(21) Regini, M. (2003). Tripartite concertation and varieties of capitalism. European $\begin{array}{llll}\text { Journal } & \text { ofIndustrial } & \text { Relations, } & \text { 9(3), }\end{array}$ https://doi.org/10.1177/09596801030093001

(22) Thibault, J. (2000). El teletrabajo: Análisis jurídico-laboral. Consejo Económico Social.

(23) Thompson, E. (1975). La formación histórica de la clase obrera en Inglaterra. Crítica.

(24) Tokman, V. (2006). Inserción laboral, mercados de trabajo y protección social.

Naciones Unidas. Serie Financiamiento del desarrollo CEPAL, (170).

https://repositorio.cepal.org/handle/11362/5143

(25) Tokman, V. (2010). El empleo en la crisis: efectos y políticas. Serie Macroeconomía del desarrollo CEPAL, (100). https://www.cepal.org/es/publicaciones/5468-empleo-lacrisis-efectos-politicas

(26) Tomei, M. (1989). El trabajo a domicilio en países seleccionados de América Latina: una visión comparativa. Cuestiones de desarrollo, documento de discusión, (29).

Cómo citar este artículo: Feregrino, M. (2021). Flexibilización laboral, teletrabajo y Covid19. Tendencias, 22(2), 371-395. https://doi.org/10.22267/rtend.212202.181 